\title{
Spatiotemporal Coordination of Rod and Cone Photoreceptor Differentiation in Goldfish Retina
}

\author{
DE BORAH L. STENKAMP, LINDA K. BARTHE L, AND PAME LA A. RAYMOND* \\ Department of Anatomy and Cell Biology, University of Michigan, Ann Arbor, Michigan 48109
}

\begin{abstract}
In this study, we have compared spatial and temporal aspects of devel opment of new rods and cones in the adult gol dfish by using combination of bromodeoxyuridineimmunocytochemistry and opsin in situ hybridization to determine the intervals between terminal mitosis (cell "birth") and expression of opsin mRNA for each photoreceptor cell type. The goldfish opsins include rod opsin and four different cone opsins: red, green, blue, and ultraviolet. In a cohort of photoreceptors born at the same time, rods expressed opsin mRNA within 3 days of cell birth, while expression of cone opsin mRNA required at least 7 days. This temporal discrepancy in differentiation, coupled with a discordance in the site of cell genesis of rods and cones, allowed opsin expression to commence in both cell types in approximately the same retinal location. Commitment to the generic cone phenotype occurred within approximately 6 days throughout the cone cohort, as indicated by expression of interphotoreceptor retinoid-binding protein (IRBP) mRNA, but expression of a specific spectral phenotype was delayed until rods differentiated nearby. Onset of expression of cone opsin mRNA followed a phenotype-specific sequence: red, then green, then blue, and finally ultraviolet; in situ hybridization with two opsin probes confirmed that individual photoreceptors expressed only onetype of opsin as they differentiated. This stepwise process of cone differentiation is consistent with the hypothesis that cell-cell interactions among developing photoreceptors may coordinate selection of specific photoreceptor phenotypes. J . Comp. Neurol. 382:272-284, 1997. ๑ 1997 Wiley-Liss, Inc.
\end{abstract}

Indexing terms: teleost; cone mosaic; opsin; IRBP; development

Generation of multiple cell types in the vertebrate retina is characterized by a stereotyped sequence of overlapping intervals of "cell birthdays" (i.e., terminal mitoses). In the mammalian retina, for example, gangl ion cells and horizontal cells are the first to be generated, followed by cone photoreceptors, then amacrine cells, and then finally rod photoreceptors, bipolar cells, and Müller glia (Sidman, 1960; LaVail et al., 1991; Carter-Dawson and LaVail, 1979). In teleost fish, the delay between the genesis of cones and rods can be considerable; for example, in some species, the retina of larval forms has cones but not rods (Blaxter and Staines, 1970; Blaxter, 1975), and in many species, production of rods throughout the differentiated retina continues into adult life (Müller, 1952; Munk and J ørgensen, 1983; Raymond, 1985; Fernald, 1989; Evans and Fernald, 1993). Because the sequence of generation of retinal cell types is conserved among a variety of taxa, cell type-specific timing of birth dates has been thought to be important for cell type specification and differentiation in the retina (Reh, 1991), although there is some evidence against this proposition (Harris and Hartenstein, 1991).

A difference in timing of the birthdates of specific cell types does not necessarily predict a corresponding sequence of cellular differentiation, as measured by expression of specific gene products. For example, Van Ginkel and Hauswirth (1994) have observed that rod opsin and cone opsin begin to be expressed concomitantly in the fetal bovine retina, suggesting that rods might mature at a faster rate than cones. In previous studies of embryonic zebrafish and goldfish, we used in situ hybridization with

Contract grant sponsor: NSF; Contract grant number: IBN-9222046; Contract grant sponsor: NIH; Contract grant number: F32 EY 06612.

*Correspondence to: Pamela A. Raymond, Department of Anatomy and Cell Biology, Medical Science II , \#4607, University of Michigan, Ann Arbor MI 48109-0616. E-mail: praymond@umich.edu

Received 20 August 1996; Revised 10 J anuary 1997; Accepted 16J anuary 1997 
specific opsin cRNAs, and we observed that all retinal cone opsin mRNAs are expressed after the onset of expression of retinal rod opsin mRNA (Raymond et al., 1995; Stenkamp et al., 1996). It seems reasonable to assume that expression of a specific opsin gene is an equivalent measure of the progression of cellular differentiation among various photoreceptor subtypes, and if so, these data suggest that rods (or at least a subset of rods) differentiate before cones. From these results, we would predict that in teleost fish, the interval between cell birth and cell differentiation (expression of opsin mRNA) is greater for cones than it is for rods. This prediction is tested in the study described here.

The teleost fish retina continues to add new neurons as long as the animal continues to grow (Müller, 1952; J ohns and Easter, 1976). The major source of these new retinal neurons (and the only source of new cone photoreceptors) is the germinal zone at the retinal margin, where an annulus of proliferative neuroepithelial cells generates new retina (Müller, 1952; J ohns, 1977). A secondary source of new retinal cells is in the outer nuclear layer (ONL), where proliferating cells are found throughout the retina; these are called rod precursors because they continuously generate rods, and only rods, which are inserted into the otherwise postmitotic ONL (Sandy and Blaxter, 1980; J ohns and Fernald, 1981). In this study, we took advantage of ongoing proliferation and differentiation in the adult goldfish retina to determine the relative intervals between birth date and opsin mRNA expression for the different photoreceptor types, by injecting bromodeoxyuridine (BrdU) into goldfish eyes and allowing variable survival times, then processing retinal sections for in situ hybridization with specific opsins in conjunction with BrdU immunocytochemistry. Since the onset of cone opsin mRNA expression is known to proceed in a stereotyped sequence in the goldfish embryo (red, green, blue, ultraviolet; Stenkamp et al., 1996), we also compared the interval from birth date to opsin expression among the 4 spectral cone photoreceptor types.

It is known that opsins are not the first photoreceptorspecific gene products to be expressed as photoreceptors differentiate. For example, interphotoreceptor retinoid binding protein (IRBP) is another photoreceptor-specific gene product (Hollyfield et al., 1985; van Veen et al., 1986; Porrello et al., 1991), and in mammalian retinas, onset of IRBP expression precedes that of rod opsin (CarterDawson et al., 1986; Gonzalez-Fernandez and Healy, 1990; Hauswirth et al., 1992). Therefore, IRBP expression may serve as an earlier indicator of photoreceptor commitment and differentiation. Wagenhorst et al . (1995) have recently cloned the goldfish IRBP, which (unlike mammalian IRBP) is expressed only in cones, and not in rods. Here we examine the relative timing of onset of expression of IRBP compared with cone opsins, in an attempt to determine whether cone differentiation is a sequential process involving first, the decision to become a cone, followed later by selection of a specific spectral cone phenotype.

\section{MATERIALS AND METHODS BrdU injections and tissue preparation}

Use of experimental animals conformed to the guidelines required by the University Committee on Use and Care of Animals (UCUCA) at the University of Michigan.
Goldfish (Carassius auratus), were obtained from a local pet store or reared in the laboratory ( ohns, 1982; Stenkamp et al., 1996), and ranged in body length from 2.0 to $6.0 \mathrm{~cm}$. Large fish $(>3.0 \mathrm{~cm})$ were anaesthetized in $0.2 \%$ tricaine methanesulfonate (MS-222; Sigma, St. Louis, $\mathrm{MO})$, and smaller fish $(<3.0 \mathrm{~cm})$ were anaesthetized in $0.05 \%$ MS-222, then wrapped in a wet paper towel and placed under a dissecting microscope. To label proliferating cells, a small incision was made with a microscalpel through the sclera at the limbus, and a Hamilton syringe with a blunt, 21-gauge needle was used to inject 0.5-5.0 $\mu \mathrm{l}$ of a $1.0 \mathrm{mM}$ solution of 5-bromo-2'-deoxyuridine (BrdU; Sigma) in sterile saline (Gratzner, 1982); the amount injected was calculated, based on eye diameter, to produce an estimated intraocular concentration of $50 \mu \mathrm{M}$. At various intervals after BrdU injection (4 hours to 15 days), fish were decapitated and eyes were enucleated. Lenses were removed, and eyes were fixed in $4 \%$ paraformaldehyde with $5 \%$ sucrose in $0.1 \mathrm{M}$ phosphate buffer for 30 minutes, then bisected along the dorsal-ventral axis and fixed for another 30 minutes, cryoprotected, and frozen in a 2:1 mixture of 20\% sucrose/OCT (Optimal Cutting Temperature, TissueTek, Elkhart, IN ); (Barthel and Raymond, 1990). In some cases, the two eyes from a single fish were removed at different time points; in these experiments fish were anaesthetized prior to removal of the first (usually left) eye, then allowed to survive until the removal of the other eye. Surviving one-eyed fish appeared healthy, behaved normally, and fed as efficiently as their two-eyed comrades.

\section{CRNA probe synthesis}

Goldfish opsin cDNA clones GFrod, GFred, GFgr-2, and GF blu were the kind gifts of K. Nakanishi and correspond to the full-length coding sequences of the rod, red, green, and blue opsins, respectively (J ohnson et al., 1993; Raymond et al., 1993). The GF uv cDNA clone was the kind gift of $\mathrm{F}$. Tokunaga and corresponds to the full-length coding sequence of the goldfish ultraviolet opsin (Hisatomi et al., 1996). The goldfish GFirbp cDNA clone was generously provided by F. Gonzalez-F ernandez and corresponds to the entire coding sequence of goldfish interphotoreceptor retinoid binding protein (IRBP). Plasmids (pBluescript) containing the goldfish cDNA inserts were linearized and used to generate digoxigenin (DIG)-labeled or fluorescein (FL)labeled CRNA sense and antisense probes by in vitro transcription from the T 7 or T3 promoter using the Genius System (Boehringer Mannheim, I ndianapolis, I N).

\section{In situ hybridization}

Procedures for in situ hybridization on retinal cryosections have been described (Barthel and Raymond, 1993; Raymond et al., 1993). Briefly, 3- or 5- $\mu$ m sections were rehydrated, digested with $10 \mu \mathrm{g} / \mathrm{ml}$ proteinase $\mathrm{K}$, treated with $0.1 \mathrm{M}$ triethanolamine containing $0.25 \%$ acetic anhydride, and dehydrated. Sections were hybridized overnight at $56^{\circ} \mathrm{C}$ with $2-10 \mu \mathrm{g} / \mathrm{ml} \mathrm{cRNA}$ in hybridization solution containing $50 \%$ formamide, then treated with RNAse A and incubated with 1:2,000 anti-DIG-alkaline phosphatase (Boehringer-Mannheim), or with 1:50 anti-DIGhorseradish peroxidase (Boehringer-Mannheim) overnight at room temperature. Hybridization was visualized using 4-nitroblue tetrazolium chloride with the substrate 5-bromo-4-chloro-3-indolyl phosphate(NBT/BCIP), or with 
TABLE 1. Presence/Absence of Double-Labeled (in situ+/BrdU +) Photoreceptors ${ }^{1}$

\begin{tabular}{|c|c|c|c|c|c|c|c|c|}
\hline $\begin{array}{l}\text { Fish \# } \\
\text { (eye) }\end{array}$ & $\begin{array}{l}\text { Days after } \\
\text { injection }\end{array}$ & $\operatorname{Rod}^{2}$ & Red $^{3}$ & Green $^{3}$ & Blue $^{3}$ & $U^{3}{ }^{3}$ & $\begin{array}{c}\text { Diff. } \\
\text { index }\end{array}$ & $\mathrm{IRBP}^{3}$ \\
\hline 1 & $1^{5}$ & $0(4)$ & N.D. & N.D. & N.D. & N.D. & 0 & $0(23)$ \\
\hline 2 & 3 & $+(8)$ & $0(40)$ & $0(31)$ & 0 (35) & $0(16)$ & 1 & N.D. \\
\hline 3 (left) & 3 & $+(4)$ & $0(9)$ & $0(25)$ & $0(26)$ & 0 (15) & 1 & N.D. \\
\hline 4 (left) & 3 & $+(8)$ & 0 (10) & 0 (11) & 0 (9) & $0(9)$ & 1 & $0(20)$ \\
\hline 5 (left) & 3 & $+(8)$ & 0 (5) & $0(6)$ & 0 (9) & $0(6)$ & 1 & $+(6)$ \\
\hline 6 (left) & 3 & $+(6)$ & 0 (12) & $0(3)$ & $0(8)$ & $0(2)$ & 1 & $+(12)$ \\
\hline 7 (left) & 3 & $+(8)$ & $0(7)$ & N.D. & N.D. & N.D. & 1 & $0(5)$ \\
\hline 7 (right) & 4 & $+(7)$ & $0(9)$ & N.D. & N.D. & N.D. & 1 & 0 (14) \\
\hline 8 & 6 & $+(8)$ & $0(40)$ & $0(31)$ & 0 (35) & $0(16)$ & 1 & $+(15)$ \\
\hline 4 (right) & 7 & $+(9)$ & $+(28)$ & 0 (15) & $0(25)$ & 0 (22) & 2 & N.D. \\
\hline 9 (left) & 7 & $+(9)$ & $+(17)$ & $0(12)$ & 0 (15) & $0(6)$ & 2 & N.D. \\
\hline 3 (right) & 7 & $+(7)$ & $+(10)$ & $+(18)$ & 0 (12) & 0 (25) & 3 & N.D. \\
\hline 10 (left) & 7 & N.D. & $+(9)$ & $+(16)$ & $+(14)$ & $+(10)$ & 5 & N.D. \\
\hline 11 & 8 & N.D. & $+(45)$ & $+(40)$ & $0(47)$ & 0 (18) & 3 & N.D. \\
\hline 5 (right) & 9 & $+(3)$ & $+(57)$ & $+(47)$ & $+(53)$ & $0(51)$ & 4 & $+(7)$ \\
\hline 12 & 9 & $+(8)$ & $+(34)$ & $+(42)$ & $+(47)$ & $+(18)$ & 5 & N.D. \\
\hline 13 & 10 & N.D. & $+(25)$ & $+(30)$ & 0 (17) & 0 (5) & 3 & N.D. \\
\hline 9 (right) & 11 & $+(3)$ & $+(16)$ & $+(6)$ & $+(15)$ & $0(6)$ & 4 & N.D. \\
\hline 6 (right) & 11 & N.D. & $+(29)$ & $+(18)$ & $+(22)$ & $+(24)$ & 5 & N.D. \\
\hline 14 & 12 & N.D. & $+(21)$ & $+(10)$ & $+(11)$ & 0 (4) & 4 & N.D. \\
\hline 15 & 12 & N.D. & $+(40)$ & $+(41)$ & $+(39)$ & N.D. & $?$ & N.D. \\
\hline 10 (right) & 15 & N.D. & $+(30)$ & $+(30)$ & $+(32)$ & $+(29)$ & 5 & N.D. \\
\hline
\end{tabular}

${ }^{1}$ N.D. = Not determined; IRBP, interphotoreceptor retinoid-binding protein; BrdU, bromodeoxyuridine.

${ }^{2}(n)=$ Number of sections examined in each eye/fish for GFrod +/BrdU + double-labeled rods.

$3(n)=$ Number of germinal zones examined for GF cone+/BrdU + double-labeled cones.

${ }^{4}$ Differentiation index $=$ number of types of photoreceptors for which a double-label ed (opsin $+/ \mathrm{BrdU}+$ ) photoreceptor was found (see Results for further description).

${ }^{5}$ Several eyes from fish with survival times of less than 1 day were al so found to contain no double-label ed (GF rod $+/ \mathrm{BrdU}+$ ) rods.

diaminobenzidine (DAB) and hydrogen peroxide (Barthel and Raymond, 1993). When evaluating sections, care was taken to ensure that all of the appropriate photoreceptors hybridized with the antisense probe in the areas analyzed, and that sense probes gave no signal.

\section{BrdU immunocytochemistry}

Sections were treated with a 1:1 mixture of $4 \mathrm{~N} \mathrm{HCl}$ and $0.5 \%$ Triton X-100 in phosphate-buffered saline (PBST) for 30 minutes to 1 hour, washed in PBST, and incubated at $4^{\circ} \mathrm{C}$ overnight with 1:50 anti-BrdU rat monodonal antibody (Accurate Chemical, Westbury, NY). Sections were washed and incubated at room temperature for 1-2 hours with 1:100 donkey anti-rat Cy3-conjugated secondary antibody (J ackson I mmunoresearch, West Grove, PA), washed and coverslipped in $100 \%$ glycerol, then viewed with a Leitz Aristoplan microscope (Leica Heerbrugg AG, Heerbrugg, Switzerland), under epifluorescence and Nomarski optics.

\section{Analysis of double-labeled photoreceptors}

Cones. Because new cones are generated exclusively in the germinal zone, the retinal regions nearest the germinal zone were examined for the presence $(+)$ or absence (0) of double-labeled (GF cone opsin+/BrdU +, or GF irbp+/BrdU +) cells. In some cases, germinal zones on each side of a given retinal section could be evaluated. Percentages of germinal zones containing double-labeled cones were calculated for each probe, for each eye.

Rods. In contrast to cones, new rods are generated throughout the outer nuclear layer where the rod precursors reside (J ohns and Fernald, 1981), and therefore, entire retinal sections were examined for the presence $(+)$ or absence (0) of double-labeled (GFrod+/BrdU +) rods. Percentages of doublelabeled rods were calculated for each retina examined as the number of doublelabeled ONL cells divided by the total number of BrdU-labeled ONL cells.
Statistics. A "differentiation index" was assigned to each retina examined based on the number of types of double-labeled photoreceptors that were observed. For example, an index of 3 indicates that doublelabeled examples of three, and only three, photoreceptor types could be found. Linear regression analyses, along with "best fit" curves (SigmaPlot, J andel Scientific, San Rafael, CA) were used to determine whether factors known to affect growth rate (temperature at which the fish were maintained, and size of fish) significantly affected the relationship between the differentiation index and the number of days after injection. In cases of sufficiently large sample size, a large sample comparison of proportions (with pooled variance, where indicated) was calculated to compare percentages of double-labeled cone photoreceptors of each subtype; this analysis allowed us to accept or reject the null hypothesis that the same percentage of double-labeled photoreceptors of each cone type was present in the same retina.

Double in situ hybridization. Hybridization was carried out as described above, but a DIG-labeled probe was combined with a different FL-labeled probe in the same hybridization solution. Hybridization signals were visualized using a cocktail of horseradish peroxidase-conjugated anti-DIG antibody and alkaline phosphatase-conjugated anti-F $L$ antibody (each at 1:50), then sequentially detected with DAB and the Vector Blue col or reaction (Vector Labs, Burlingame, CA), respectively. Spatial relationships of newly differentiated photoreceptors of each subclass were examined by measuring the distance between the most immature (nearest the germinal zone) photoreceptor that hybridized with a cone opsin probe, and the central limit of the germinal zone (defined as the beginning of the outer plexiform layer; see Figs. 2B and 5B). Phase contrast images were collected with a Kodak DCS digital camera (Eastman Kodak, Rochester, NY) interfaced with a Power Maclntosh 7100, and measurements were made using $\mathrm{NIH}$ I mage 1.59. In sections hybridized with two opsin 


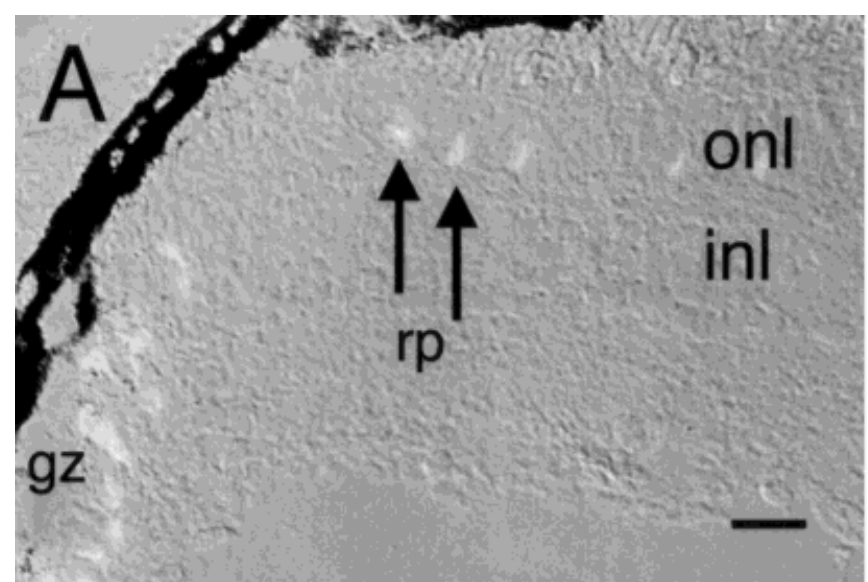

Fig. 1. Cell proliferation and growth at the goldfish retinal margin. A: Retinal cryosection from a fish injected intraocularly with bromodeoxyuridine (BrdU) and killed 1 day later; double exposure (Nomarski optics and epifluorescence). Cluster of mitotic cells in the germinal zone, gz; representative mitotic rod precursors, rp; outer nucl ear layer, onl; inner nuclear layer, inl. B: Retinal cryosection from a fish injected

probes, the shorter distance was calculated as a fraction of the longer distance, in order to compare material obtained from different fish. In cases of sufficiently large sample size, the resulting ratios were statistically compared using an unpaired Student's t-test.

Photography. Non-fluorescent images were photographed with Ektachrome 160 film (Eastman Kodak, Rochester, NY) using Nomarski interference-contrast optics, and images containing fluorescent cells were photographed using serial, double exposures (epifluorescence followed by Nomarski optics). The 35-mm col or slides were digitized onto a Kodak Photo $C D$, the images were adjusted using Adobe Photoshop 3.0 (Adobe Systems, Mountain View, CA) to match contrast and color balance, and then printed on a Kodak XL8600 dye-sublimation printer.

\section{RE SULTS \\ The adult goldfish retinal margin represents a developmental timeline}

To establish the characteristics of retinal growth and differentiation at the retinal margin, fish were injected with BrdU, and eyes were removed 1 or 15 days later and processed for BrdU immunofluorescence. Radial retinal cryosections at 1 day after BrdU injection showed two major mitotic retinal cell populations: (1) cells that comprise the germinal zone at the retinal margin, and (2) a subpopulation of outer nuclear layer (ONL) nuclei identified as rod precursors by their position and morphology (Fig. 1A); (see alsoJ ohns, 1977; J ohns and Fernald, 1981). Typically, rod precursors were more abundant in a region 40-100 $\mu \mathrm{m}$ from the germinal zone; a peripheral accumulation of rod precursors has been observed previously, and this region is referred to as the "growth zone" (Knight and Raymond, 1990), or "secondary germinal zone" (Fernald, 1989).

At 15 days after BrdU injection, the relative positions of germinal zone-derived cells and rod precursor-derived cells could be determined. In accord with previous studies

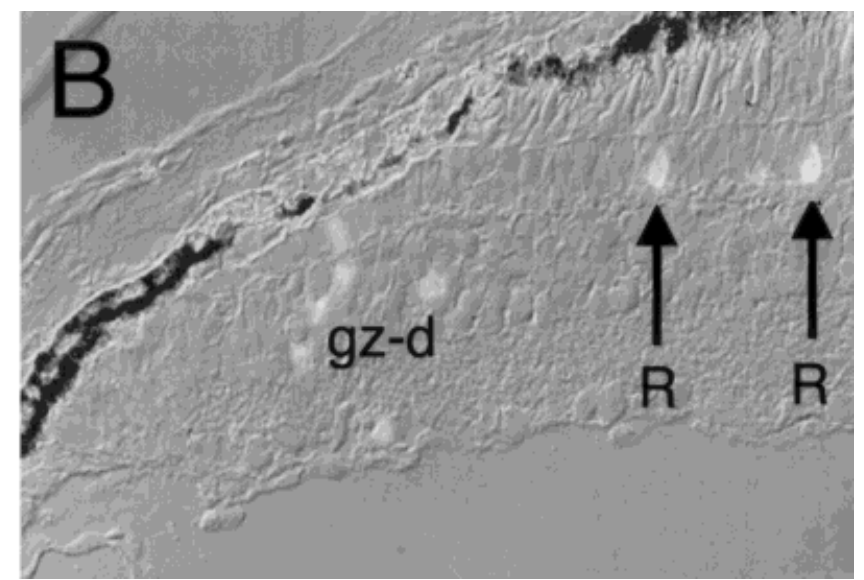

intraocularly with BrdU and allowed 15 days survival; double exposure (Nomarski optics and epifluorescence). The cohort of fluorescent cells that were mitotic in the germinal zone at the time of injection, gz-d (germinal zone-derived); rod-precursor-derived rod photoreceptors, R. Scale bar $=20 \mu \mathrm{m}$.

(J ohns, 1982; Mack and Fernald, 1995), the BrdU-labeled cohort of cells nearest thegerminal zone (presumed to be of germinal zone origin and generated 15 days previously) was a nearly contiguous wedge of label ed cells spanning all three nuclear layers; these cells were displaced toward the center of the retina by the later generations of (unlabeled) cells added at the germinal zone during the interval after the injection (Fig. 1B). The region of the retina adjacent to the germinal zone therefore represents a developmental "timeline"-the cells closest to the germinal zone are the youngest, and those farther from the germinal zone are progressively older.

Cells derived from rod precursors were also labeled with BrdU, but they were present throughout the $O N L$, in higher numbers in a region $40-100 \mu \mathrm{m}$ from the BrdUlabeled, germinal zone-derived cohort (Fig. 1B). These observations suggest that cell addition and differentiation in the interval following the injection did not change the spatial relationships of the two previously mitotic cell populations.

\section{Expression of opsin mRNA is detectable in rods by 3 days after cell birth}

Several fish were injected with BrdU, allowed varying survival times, and the eyes were sectioned and processed for in situ hybridization with a cRNA riboprobecorresponding to the gene for rod opsin (GFrod), followed by BrdU indirect immunofluorescence. Each eye was scored for the presence $(+)$ or absence $(0)$ of double-labeled cells (Table $1)$. Because the hybridization reaction product was localized to the perinuclear region of rod photoreceptors (Raymond et al., 1993) and because BrdU was incorporated into the photoreceptor nudeus, rod cell bodies that weredoublelabeled for opsin and BrdU could be identified as cells with a fluorescent nucleus capped by hybridization reaction product (Fig. 2A). These rod opsin+/BrdU + cells were found in the ONL of retinas from fish at survival times of 3 days or more, but not in retinas from fish killed one day or 


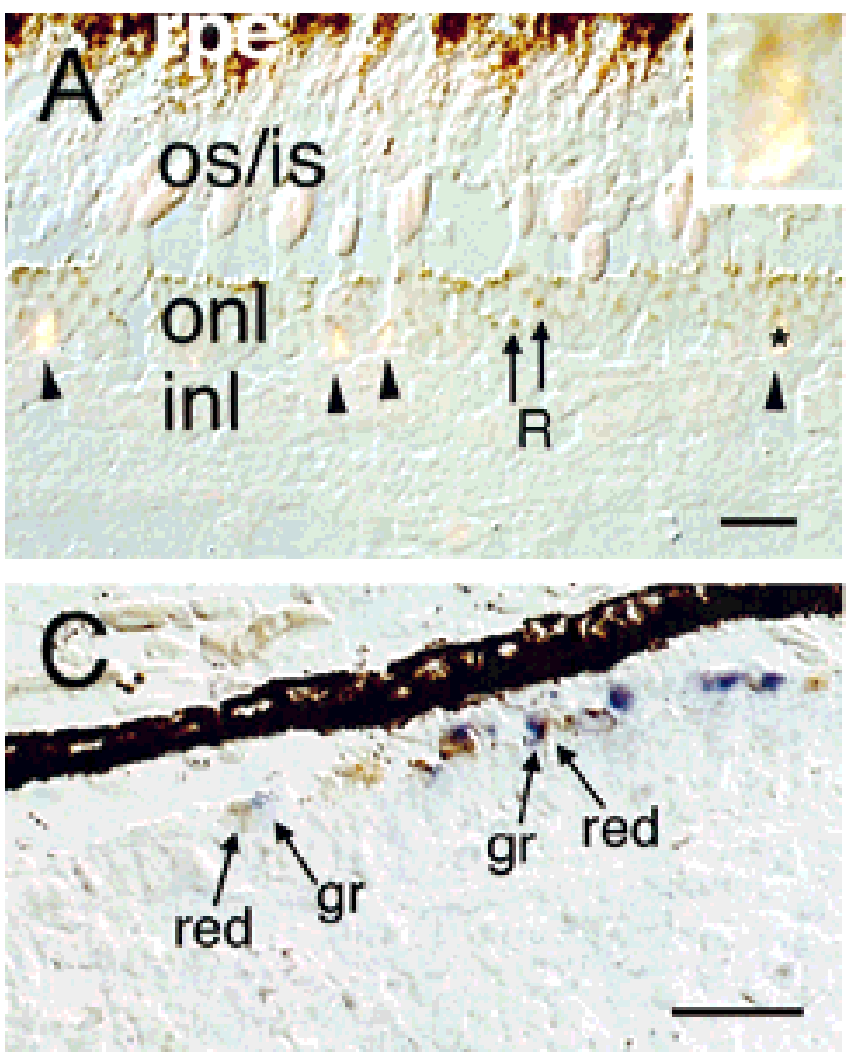

Fig. 2. A: Retinal cryosection from a fish injected with BrdU and allowed 4 days survival; in situ hybridization with GFrod CRNA (visualized with diaminobenzidine; DAB), and immunofluorescence with anti-BrdU (visualized with Cy3 immunofluorescence). Many of the cell bodies in the outer nuclear layer, onl, hybridized with the GFrod probe; two representative rods, R. Four ONL cells in this field are labeled by BrdU (arrowheads); all but the one on the left also hybridized with GFrod. A double-labeled rod (asterisk) is shown at higher magnification $(1,400 \times)$ in the inset. Inner nuclear layer, inl; inner and outer segments, os/is; retinal pigmented epithelium, rpe. B: Retinal cryosection from a fish injected with $\mathrm{BrdU}$ and allowed 11 days survival, hybridized with GFred cRNA (visualized with 4-nitroblue tetrazolium chloride and 5-bromo-4-chloro-3-indolyl phosphate, NBT/ $\mathrm{BCIP}$ ), and Cy3 immunofluorescence; double exposure (Nomarski optics and epifluorescence). A subpopulation of mature cones hybridized with the GF red probe (purple reaction product) ; a representative red cone is indicated (red). A cohort of BrdU-labeled (fluorescent) cells

less after BrdU injection (Table 1). Therefore, the time between rod cell birth and rod opsin expression was greater than 1 and less than or equal to 3 days. (The intent of these experiments was not to measure an exact interval between cell birth and opsin expression, but rather to provide a means to compare this interval for different photoreceptor cell types.) From 30 to $50 \%$ of the BrdUlabeled cells in the ONL of 3-day retinas also hybridized with the rod opsin probe, while as many as $90 \%$ of the $\mathrm{BrdU}$-labeled cells in ONL of the 4- to 11-day retinas were double-labeled. We never observed $100 \%$ of the BrdUlabeled, ONL cells to be double-labeled, but this was expected since dividing rod precursors, like other stem cell populations, are self-perpetuating as well as rod-generat-
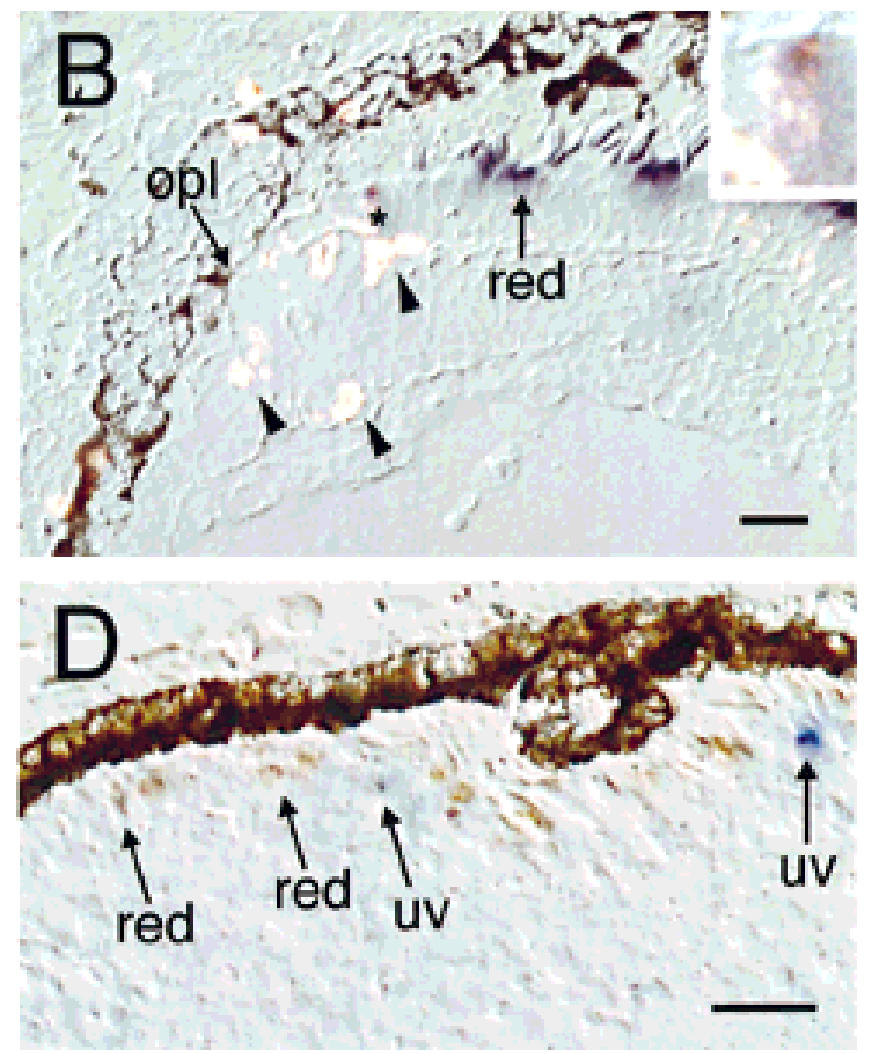

is indicated (arrowheads). A single immature cone shows both the hybridization reaction product and BrdU immunofluorescence (asterisk) and is shown at higher magnification $(1,400 \times)$ in the inset. The beginning of the outer plexiform layer, opl, was used as a landmark for measuring and comparing relative distance of differentiating cones to the germinal zone (see Methods). C: Retinal cryosection hybridized with a combination of digoxigenin (DIG)-labeled GF red riboprobe, and fluorescein (FL)-labeled GF gr-2 riboprobe, visualized with DAB and Vector Blue, respectively. Red cones (red), contain the brown reaction product, and green cones (gr) contain the blue reaction product. D: Retinal cryosection hybridized with a combination of DIG-labeled GF red riboprobe, and FL-labeled GFuv riboprobe, visualized with $\mathrm{DAB}$ and Vector Blue, respectively. Red cones contain the brown reaction product, and UV cones (uv) contain the blue reaction product. Note that the distance separating the youngest red and youngest green cone (in C) is much less than the distance separating the youngest red and youngest UV cone (in D). Scale bars $=20 \mu \mathrm{m}$.

ing, and so some of the progeny of BrdU-labeled cells represented mitotic rod precursors (Raymond and Rivlin, 1987; Knight and Raymond, 1990).

\section{Opsin expression in cones is delayed until 7 to 12 days after cell birth, and is initiated in the order: red, green, blue, ultraviolet}

Additional retinal cryosections were processed for in situ hybridization with a cRNA riboprobe corresponding to one of the four goldfish cone opsin genes, and then processed for BrdU immunocytochemistry. An attempt was made to hybridize sections from each retina with each of the five opsin probes (rod, red, green, blue, UV), so that the 
presence $(+)$ or absence $(0)$ of doublelabeled (opsin + / $\mathrm{Brdu}+$ ) photoreceptors of each subtype could be determined for every eye (Table 1). In morphologically mature cones, the hybridization reaction product was located in the proximal region of the inner segment, as described previously (Raymond et al., 1993). In morphologically immature cones near the retinal margin, the hybridization signal was localized to the apical portion of the cell, but the inner segment had not yet begun to develop (Fig. 2B). Photoreceptors double-labeled for cone opsin mRNA and $\mathrm{BrdU}$ were identified by apical reaction product associated with a fluorescent nucleus (Fig. 2B). Double-labeled cones were typically located 40-100 $\mu \mathrm{m}$ from the retinal margin, and neighboring cells in other retinal layers were also labeled by BrdU.

Doublelabeled (cone opsin+/BrdU + ) cones were not found at survival times less than 7 days, and when present, double-labeled (rod opsin $+/ \mathrm{BrdU}+$ ) rods were also always present (Table 1). The interval between cell birth and opsin expression, as measured for a cohort of photoreceptors born at approximately the same time, was therefore much greater for cones ( $\geq 7$ days) than it was for rods ( $\leq 3$ days).

A comparison of the presence or absence of doublelabeled cones of each subtype indicated that cones differentiated sequentially (Table 1). For example, if a retina contained double-labeled UV cones, it also always contained doublelabeled blue, green, and red cones. However, if there were double-label ed blue cones, there were always double-labeled green and red cones, but not al ways doublelabeled UV cones. Similar comparisons of the other cone opsins lead to the inference that a cohort of cones born at the same time differentiates in an order defined by their spectral phenotype: red, then green, then blue, and finally ultraviolet.

To determine the average interval between cell birth and opsin expression for each photoreceptor type, each eye was assigned a "differentiation index" (see Materials and Methods). The average survival time corresponding to each differentiation index, indicating the average interval between cell birth and expression of opsin mRNA, was $3.5 \pm$ 1.0 days for rods, $7.0 \pm 0$ days for red cones, $8.3 \pm 1.2$ days for green cones, $10.5 \pm 1.2$ days for blue cones, and $10.3 \pm$ 3.0 days for UV cones (Fig. 3). The only significant difference in timing was that between rods and all cone types (Student's t test, $\mathrm{P}<0.001$ ). Therefore, despite a consistent order of cone differentiation in a given fish, the amount of time required for detectable opsin expression varied considerably among individuals. It is known that the rate of growth varies among individual fish of a given species (Brown, 1957), and perhaps cellular differentiation also proceeds at different rates. However, when fish were sorted according to temperature at which they were maintained, or grouped by size (two factors known to affect the growth rate of tel eosts, Brown, 1957; J ohns, 1982), no clear effects on the average temporal interval between photoreceptor cell birth and opsin mRNA expression were evident (temperature: see Fig. 3; size: data not shown). We did not attempt to control individual factors (e.g., feeding behavior, hormonal status, etc.) that may also have contributed to variability in rates of growth and differentiation.

To further clarify the sequence of cone differentiation, we removed the two eyes from a given fish at different

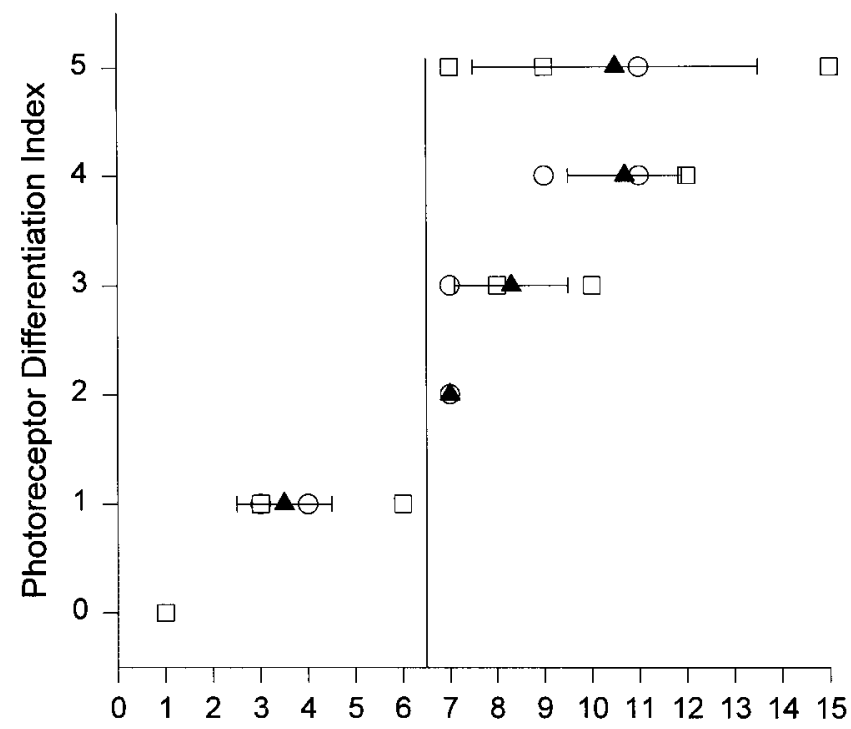

Days After Injection

Fig. 3. Photoreceptor differentiation index as a function of survival time. Photoreceptor differentiation index corresponds to the number of spectral types of double-labeled photoreceptors that were present in each retina ( $1=$ rods only; 2 = rods and red cones; 3 = rods and red and green cones; 4 = rods and red, green, and blue cones; $5=$ all photoreceptor types). Open squares indicate fish maintained at $20^{\circ} \mathrm{C}$ Open circles indicate fish maintained at $26^{\circ} \mathrm{C}$. The average (means \pm standard deviation) survival times observed for each differentiation index are indicated by filled triangles. The vertical line (at 6.5 days) separates retinas expressing only rod opsin from those expressing rod plus one or more cone opsins.

times; in this way, we eliminated individual variability in rates of differentiation. Seven fish were processed in this manner and analyzed for double-labeled (opsin $+/ \mathrm{BrdU}+$ ) photoreceptors (Table 1). The percentage of double-labeled photoreceptors was calculated for each cone type in each eye (results from four fish are presented in Fig. 4). For example, the left eye of fish 4 (removed at 3 days), had only double-labeled rods, but the right eye (removed at 7 days) contained double-labeled rods and double-label ed red cones, confirming that rod and cone photoreceptors born at approximately the same time differentiate at different rates. Similarly, the left eye of fish 5 (removed at 3 days) contained only double-labeled rods, but the right eye (removed at 9 days) contained double-labeled rods, red cones, green cones, and blue cones, with fewer numbers of each successive cone type. Similarly for fish 6, although the right eye (11 days after BrdU injection) contained double-labeled cones of all types including UV cones. Statistical analysis using a large sample comparison of proportions was performed for fish 4 (7 days), fish 5 (9 days), and fish 6 (11 days). The difference in the size of the double-labeled cell populations was weakly significant for red vs. green $(P<0.01$ using pool ed variance for fish 5 and $6)$, and highly significant for green vs. blue ( $P<0.01$ for fish 4, 5, and 6), and for blue vs. UV (P $<0.0001$ for fish 5 and 6).

The quantitative differences in the size of the double labeled cone populations may have been, in part, a conse- 

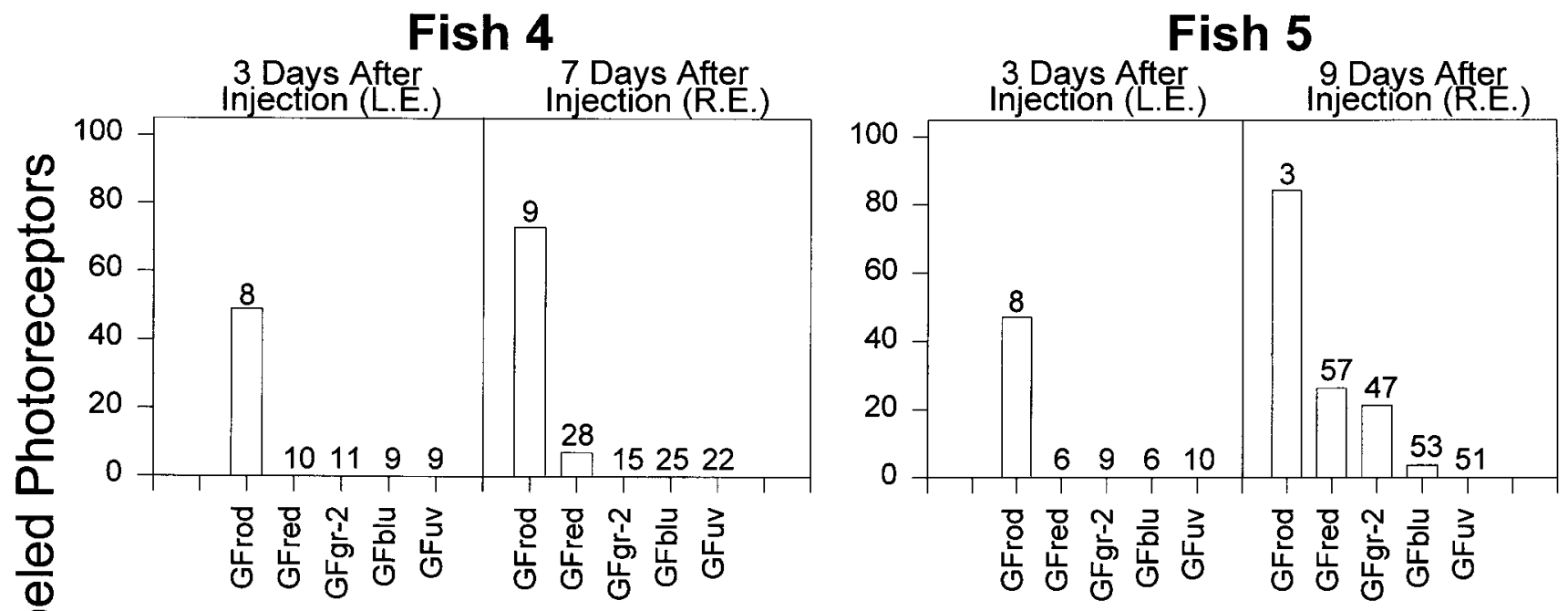

Fish 6
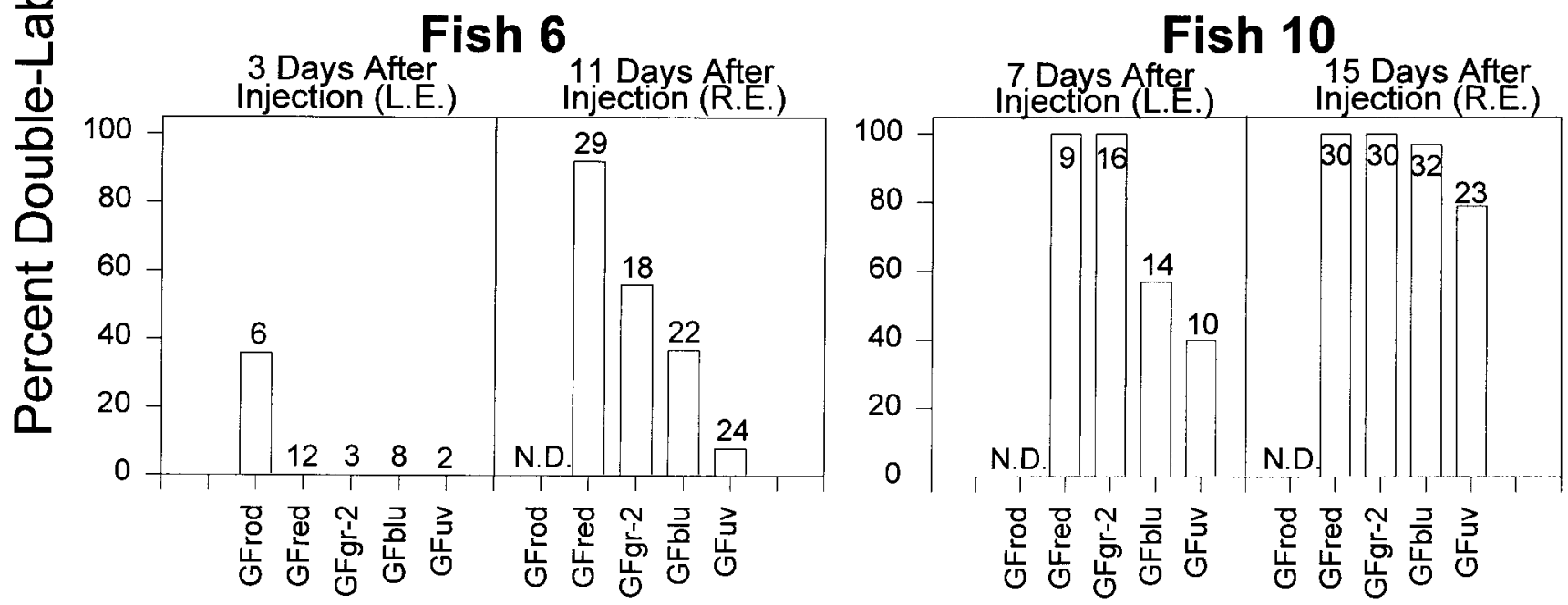

Fig. 4. Comparison of the percentage of opsin $+/ B r d U+$ doublelabeled cells in eyes removed from the same fish at different times after BrdU injection. For rods, "percent double-labeled" values were calculated as the percentage of BrdU + ONL cells that also hybridized with GFrod (number of sections examined is shown above the bars).

quence of the differences in the relative numbers of different cone types. There are approximately equal numbers of red and green cones and approximately equal numbers of blue and UV cones, but only half as many blue/UV as red/green in adult/juvenile goldfish retina (Marc and Sperling, 1976; Stell and Hárosi, 1976; Raymond et al., 1993). However, the apparent order of differentiation at the retinal margin cannot be explained by this factor alone, since there were clear differences in red vs. green double-labeled populations, and in blue vs. UV double-labeled populations despite nearly equivalent total numbers, respectively (Fig. 4). Furthermore, in some eyes there were double-labeled red cones but no double-labeled green cones (fish 9; Table 1, Fig. 4), or double-labeled blue cones without double-labeled UV cones (fish 5; Table 1, Fig. 4). Given a long enough interval, the frequency of double-label ed cones approached $100 \%$ (fish 10; Fig. 4).
For cones, "percent double labeled" values were calculated as the percentage of $\mathrm{BrdU}+$ growth zones which contained double-labeled cones of the indicated phenotype (number of growth zones examined is shown above bars). Not determined, N.D.; Left eye, L.E.; Right eye, R.E.

\section{Differentiating goldfish photoreceptors express only one type of opsin}

Theinterpretation of the aboveresults depends upon the continuity of specific opsin expression in an individual photoreceptor, since an alternative explanation of these results is that all cones initially express red opsin mRNA, then later switch to a different opsin which defines their mature phenotypes. To examine this possibility, we performed several double in situ hybridizations with two different opsin probes. This method involves combining two specific opsin riboprobes, one labeled with digoxigenin $(D I G)$, the other with fluorescein $(F L)$, and subsequent visualization with an antibody/color reaction series that generates a brown or blue precipitate, respectively. When these two probes hybridize within the same cell, a distinct, dark col or product is generated (see below). 
TABLE 2. Ratio of Distances of Newly Differentiating Photoreceptors From the Germinal Zone ${ }^{1}$

\begin{tabular}{|c|c|c|c|c|c|}
\hline \multirow[b]{2}{*}{ Numerator } & \multicolumn{5}{|c|}{ Denominator } \\
\hline & Rod & Red & Green & Blue & UV \\
\hline Rod & (1.0) & $\begin{aligned} 0.60 & \pm 0.13 \\
\mathrm{n} & =9\end{aligned}$ & $\begin{array}{c}0.71 \\
n=2\end{array}$ & N.D. & $\begin{aligned} 0.24 & \pm 0.13 \\
\mathrm{n} & =5\end{aligned}$ \\
\hline Red & & (1.0) & $\begin{aligned} 0.64 & \pm 0.15 \\
\mathrm{n} & =4\end{aligned}$ & $\begin{aligned} 0.38 & \pm 0.11 \\
\mathrm{n} & =8\end{aligned}$ & $\begin{aligned} 0.28 & \pm 0.10 \\
\mathrm{n} & =9\end{aligned}$ \\
\hline Green & & & (1.0) & N.D. & $\begin{aligned} 0.19 & \pm 0.11 \\
\mathrm{n} & =3\end{aligned}$ \\
\hline Blue & & & & (1.0) & $\begin{array}{c}0.82 \\
n=2\end{array}$ \\
\hline
\end{tabular}

${ }^{1 N}$.D., these riboprobe combinations were not done; $n=$ number of growth zones analyzed.

Goldfish retinal cryosections were processed for double in situ hybridization, by using all possible combinations of opsin probes, and 43 growth zones were examined. In no case was a double-labeled cell found (Fig. 2C,D). These results indicate that goldfish cones express only one type of opsin mRNA from the earliest stages of cellular differentiation.

\section{The spatial relationships of differentiating cones are consistent with the temporal order of differentiation: red, green, blue, ultraviolet}

Differentiating cones labeled by the double in situ procedure were characteristically positioned relative to each other. For example, the youngest opsin mRNAexpressing red cone was al ways closer to the germinal zone than the youngest opsin mRNA-expressing cone of any other type, and the youngest opsin-expressing UV cone was always more distant from the germinal zone than any other cone type (e.g., Fig. 2C,D). We quantified these results by measuring the distance between the youngest photoreceptor of each type and the proximal limit of the germinal zone (identified as the beginning of the outer plexiform layer, see Fig. 2B). To eliminate variability due to differences in growth/differentiation rate or obliqueness of section planes, we compared these distances independently for each cryosection, calculating the ratio of the smaller to the larger distance (Table 2 ). A ratio near 1.0 would indicate that the two cone types were at a similar distance from the germinal zone at the onset of opsin expression, and ratios less than 1.0 indicate a discrepancy in relative distance from the germinal zone. In those cases in which the sample size was sufficiently large to compare ratios statistically, the following comparisons were significant: red/green vs. red/UV; red/green vs. red/blue; and $\mathrm{rod} / \mathrm{red} \mathrm{vs}$. rod/UV (Student's t test; $\mathrm{P}<0.01$ ). These comparisons indicate that differentiation of blue and UV cones was separated in space (and therefore in time) from the differentiation of rods, red and green cones, consistent with the temporal order of opsin mRNA expression determined in the BrdU double-label study.

\section{Onset of opsin expression of both rods and cones occurs in the same general location}

Because the sources of rods and cones in the adult goldfish retina are distinct and because the interval between cell birth and opsin mRNA expression was found to be different for cones compared with rods, it was of interest to determine the locations of newly differentiating rods and cones relative to each other and to other retinal landmarks. To compare the locations of the youngest differentiating cone with the rod precursors in the growth zone, eyes were injected with BrdU, fish were allowed to survive for 1 day, and radial retinal cryosections were processed for cone opsin in situ hybridization, combined with BrdU immunofluorescence. The youngest opsinexpressing cone was always located in the growth zone, near the most peripheral rod precursor (data not shown).

To compare the location of differentiating cones with that of differentiating rods, two experiments were performed. First, eyes were injected with BrdU, fish were allowed to survive for 3 days, and then radial retinal cryosections were processed for cone opsin in situ hybridization with BrdU immunofluorescence. In this case, the youngest opsin-expressing cone was flanked by the peripheral cluster of new rods (data not shown). Since these new rods were "3-days-old," it is likely that some of them also expressed rod opsin (see Table 1), suggesting that the newly differentiating cones began to express opsin when they were near a differentiating rod.

The second experiment confirmed that rods and cones began to express opsin in the same general retinal location. Cryosections processed for double in situ hybridization with a combination of red cone opsin riboprobes and rod opsin riboprobes, showed that the peripheral limit of opsin expression in both rods and red cones was generally similar; compared with the youngest opsin-expressing red cones, the youngest opsin-expressing rods were always slightly closer to the germinal zone (Fig. 5A). Therefore, although rods and cones were generated in two separate locations, differences in rate of differentiation resulted in spatially contiguous onset of opsin expression.

\section{Goldfish cones express interphotoreceptor retinoid-binding protein (IRBP) before they express a specific opsin}

By using riboprobes generated from the goldfish IRBP (GFirbp) CDNA (Wagenhorst et al., 1995), we confirmed that IRBP mRNA was localized to cones, but not rods, and also to a rare population of unidentified cells in the inner nuclear layer (Fig. 5B). We established the interval between cell birth and IRBP expression (for comparison with the interval between cell birth and cone opsin expression) using the BrdU-injected eyes described above. Doublelabeled (GFirbp+/BrdU +) cells were present in several of the retinas examined (Fig. 5B), and in many cases they were present in retinas that contained no examples of opsin double-labeled cones (Table 1). In the case of fish 8, the sample size was sufficiently large for a statistical comparison of the proportions of GFirbp +/BrdU + and red cone opsin $+/ \mathrm{BrdU}+$ cells, and the difference was found to be highly significant $(P<0.001)$.

To confirm that IRBP mRNA was expressed in nascent cones prior to expression of opsin mRNA, we performed double in situ hybridization using a combination of $F L$ labeled GFirbp cRNA and DIG-labeled GF red cRNA (Fig. 5C). The youngest, IRBP-expressing presumptive cone was always located nearer to the germinal zone than the youngest, red cone opsin-expressing cone. Additionally, all cells that expressed red cone opsin al so expressed IRBP, as 


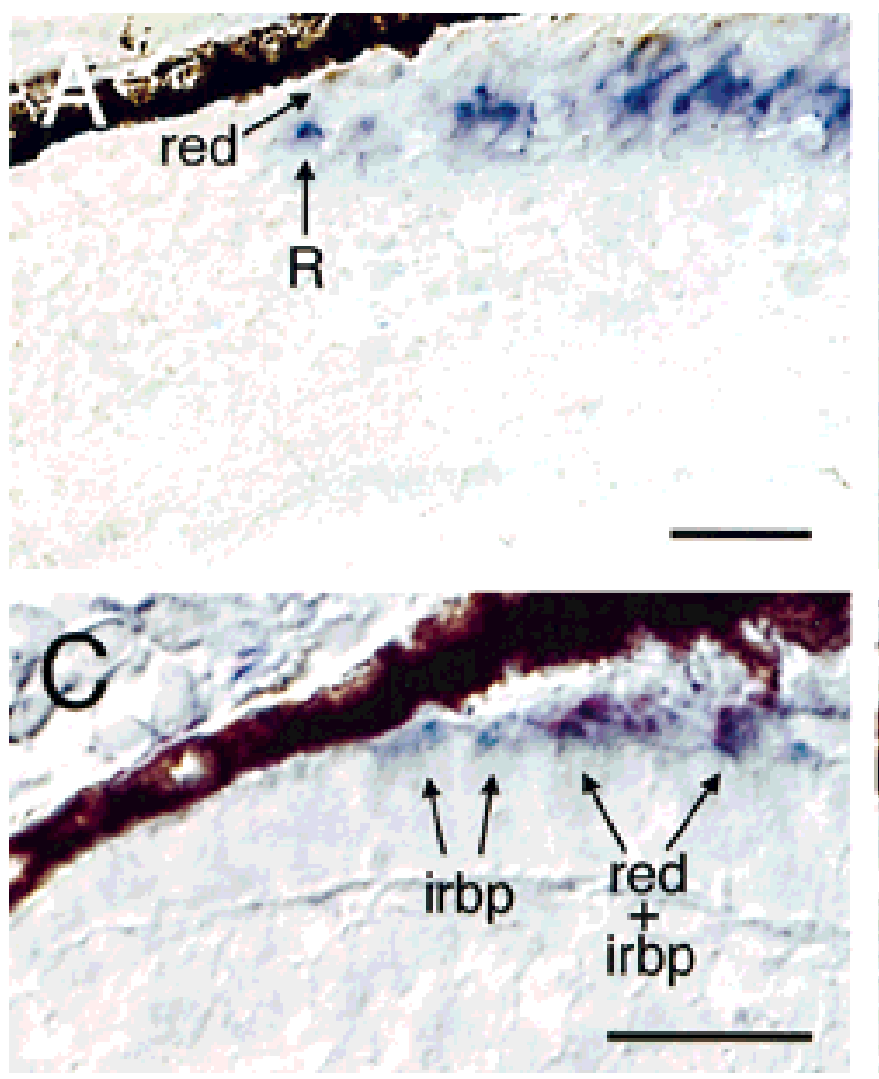

Fig. 5. Relative locations of newly differentiating rods and cones. A: Retinal cryosection hybridized with a combination of a FL-labeled GFrod riboprobe (visualized with Vector Blue) and a DIG-labeled GF red riboprobe (visualized with DAB). The youngest opsin-expressing red cone (red) is located approximately $5 \mu \mathrm{m}$ central to the youngest opsin-expressing rod, R. B: Retinal cryosection from fish 8, injected with BrdU and allowed 6 days survival, hybridized with GFirbp riboprobe (visualized with NBT/BCIP), and labeled with anti-BrdU (visualized with Cy3 immunofluorescence); double exposure (Nomarski and epifluorescence). IRBP mRNA (irbp; purple hybridization reaction product) is present in the inner segments of all cone types, as well as in a subpopulation of inner nuclear layer cells. A morphologically undifferentiated cone hybridized with GFirbp is also labeled by BrdU (asterisk). Note that no double-labeled (opsin+/ $\mathrm{BrdU}+$ ) cones were found in fish 8 (see Table 1). opl, outer plexiform

indicated by the presence of a dark reaction product, characteristic of co-localization of both riboprobes (Fig. $5 \mathrm{C})$. Taken together, these data indicate that cones begin to express IRBP mRNA at an earlier stage in their maturation compared with opsin mRNA.

A number of additional combinations of in situ hybridization and BrdU immunocytochemistry were applied to retinal cryosections to determine the relative location of the youngest IRBP-expressing cone. IRBP expression was typically initiated peripheral to the most peripheral rod precursors (data not shown), and also on the peripheral side of the youngest opsin-expressing rod (Fig. 5D). Therefore, expression of a cone-specific gene commenced before the nascent cones encountered rod precursors or differentiating rods, although the expression of a specific cone opsin was delayed until rod-precursor-derived cells were generated in their vicinity.
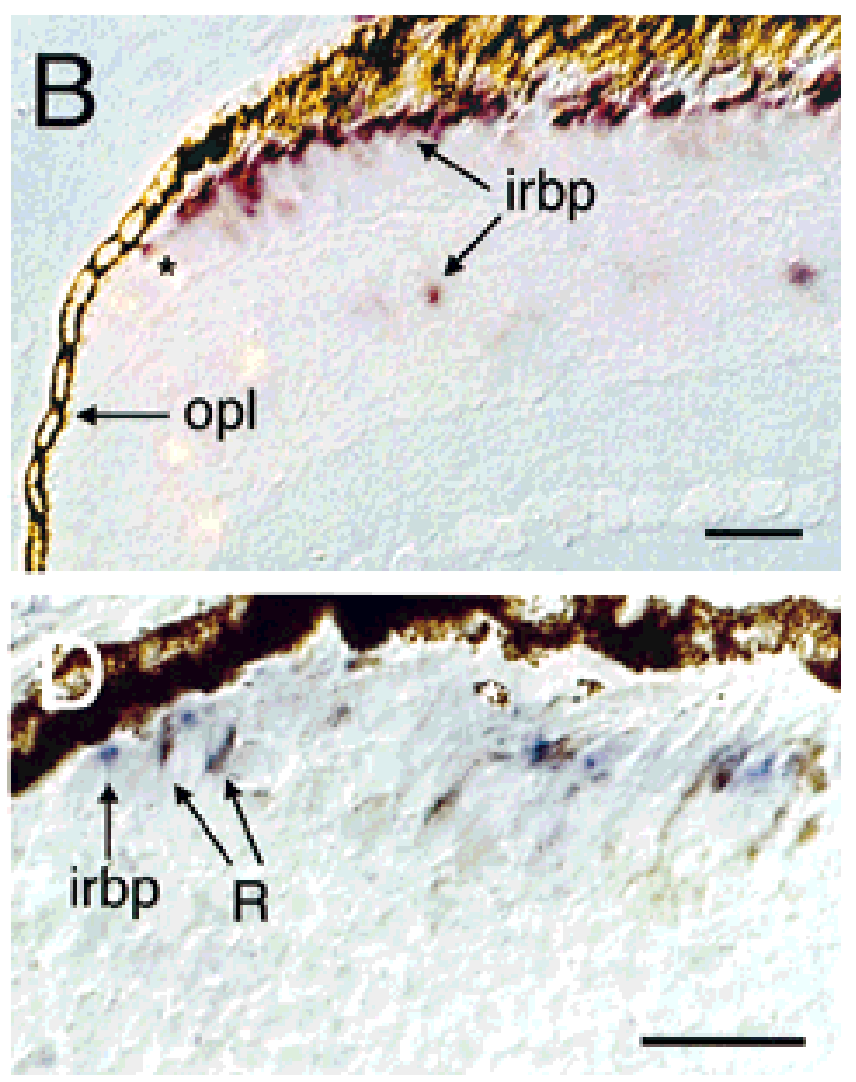

layer. C: Retinal cryosection hybridized with a combination of a FL-labeled GFirbp riboprobe (visualized with Vector Blue), and a DIG-labeled GF red riboprobe (visualized with DAB). Red cones hybridize with both probes (red + irbp); note the dark precipitate characteristic of colocalization of Vector Blue and DAB (color is deep purple in this preparation). Other cones (irbp) hybridize only with GFirbp and therefore contain the blue reaction product. D: Retinal cryosection hybridized with a combination of GFirbp (visualized with Vector Blue) and GF rod (visualized with DAB). Cones (irbp) hybridize with GF irbp (blue reaction product); rods $(\mathrm{R})$ hybridize with GF rod (brown reaction product). A fragment of retional pigmented epithelium is indicated by a white asterisk to avoid confusion with the brown DAB color product. In the region to the left of the asterisk, cones are obscured by a tissue artifact. Scalebars $=20 \mu \mathrm{m}$.

\section{DISCUSSION Goldfish photoreceptors express only one type of opsin during maturation}

Photoreceptor cell types are classically distinguished by nuclear morphology and position, by size and shape of inner and outer segments, as well as by spectral sensitivity and expression of a specific opsin (Cohen, 1972). Developing photoreceptors, however, show fewer morphological distinctions, and recent evidencesuggests that even expression of a specific opsin may not be a useful means of categorizing photoreceptors, since they may switch from one type of opsin to another as they develop (Szél et al., 1994). Because we used specific opsin mRNA expression as a means of identifying photoreceptor subtypes in the devel oping retina, it was important to determine whether goldfish photoreceptors similarly switch opsins. Evidence 
from earlier experiments suggests that retinal photoreceptors in embryonic goldfish express only one type of opsin, since the number of photoreceptors hybridized by a combination of two distinct opsin riboprobes is additive (Stenkamp et al., 1996). In the present study, we addressed this question more directly by using a technique that allows simultaneous detection of two different opsin mRNAs in the same cell. The retinal margin of adult goldfish was studied (rather than the embryonic retina) to analyze several stages of photoreceptor differentiation in a single preparation. We never observed colocalization with any combination of twoopsin riboprobes in the same photoreceptor cell, suggesting that goldfish photoreceptors at all stages of differentiation express only onetype of opsin gene.

\section{Cone opsin expression is delayed compared with rod opsin expression}

The most important finding of this study is that the order of photoreceptor cell genesis in the retina does not predict the order of cell differentiation, as indicated by onset of expression of opsin mRNA. Previous work suggested that cones are born before rods in the goldfish retina (Raymond and Rivlin, 1987), but, surprisingly, rods express opsin before cones do (Raymond et al., 1995; Stenkamp et al., 1996). However, the earlier studies examined onset of opsin expression in the absence of direct information regarding cell birthdate. In the present study, we have taken advantage of ongoing proliferation and differentiation in the adult gol dfish retina to determine the order of onset of opsin expression in a cohort of cells born at approximately the same time. By using this technique, we haveclarified the temporal interval between cone cell birth and opsin expression, and we found that it is significantly longer than the corresponding interval between rod cell birth and opsin expression. This finding resolves the apparent discrepancy between the order of photoreceptor cell genesis and the order of photoreceptor opsin expression.

Several previous studies have determined that morphological differentiation of cones precedes that of rods in fish and rodents: definitive rod nuclei cannot be recognized until after cone nuclei are present (Raymond, 1985; Kljavin, 1987), and rod outer segment formation and synaptogenesis are delayed compared with cone morphogenesis (Smelser et al., 1974; Branchek and BreMiller, 1984; Raymond, 1985). The results of the present study indicate that the degree of morphological maturation may not adequately reflect the continuum of events leading from cell birth to cell commitment and differentiation.

\section{Cone differentiation is a stepwise and protracted process}

The relatively long interval ( 7 to 12 days) between cone cell birth and cone opsin expression in the adult goldfish retina was also surprising. I mmature cones were morphologically recognizable several days before they expressed a specific opsin mRNA, so we suspected that they might express other cone-specific markers before opsin. In Xenopus retina, for example, photoreceptors can be identified by the presence of cone- and rod-specific antigens before they display specific opsin immunoreactivity (Harris and Messersmith, 1992). Similarly, we found that cones began to express a cone-specific marker, IRBP, by 6 days, independent of their eventual spectral phenotype. This suggests that cone differentiation is a stepwise process of pheno-

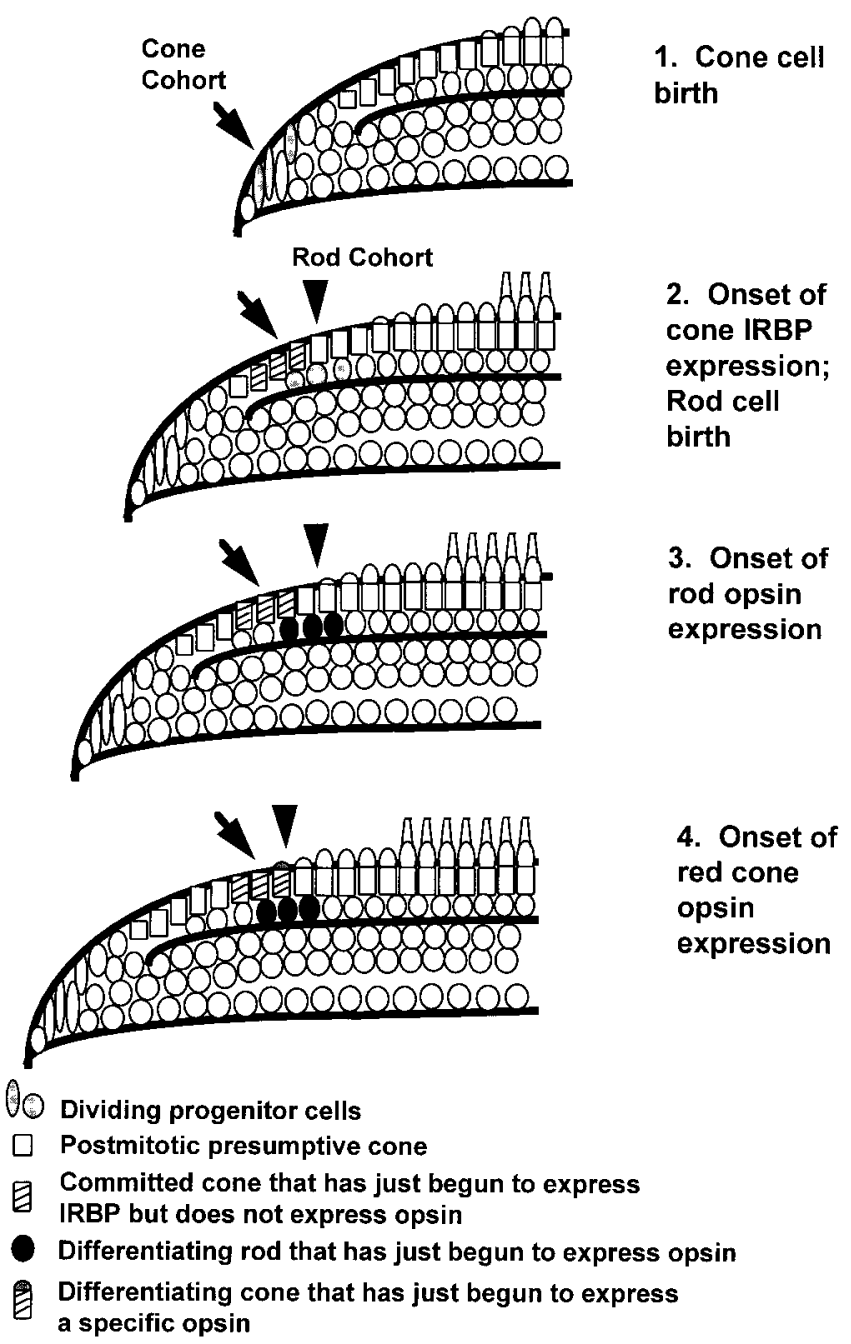

Fig. 6. Early life histories of rods and cones in adult goldfish retina. A cohort of cones (arrow) and a cohort of rods (arrowhead) are followed from cell birth until the onset of opsin expression. See Discussion for additional description.

typic acquisition, in that first the "decision" to become a cone is made, as evidenced by expression of a general cone marker, followed by the manifestation of a specific spectral phenotype, as evidenced by expression of a specific opsin gene. Further insights from this observation related to the concomitant process of rod differentiation are discussed later.

The sequence of events that take place as cone photoreceptors differentiate is illustrated in Figure 6 . Cones are generated in the germinal zone at the margin of the retina, and become morphologically identifiable as prospective cones when they adopt a cuboidal shape and at their basal surfaces synaptic terminals begin to form, creating the outer plexiform layer (Raymond, 1985). By 6 days after birth in the germinal zone, these presumptive cones begin to express IRBP (Table 1), but opsin expression is delayed for one or more additional days. We did not attempt to determine the time necessary for complete morphological maturation of cones in the adult goldfish retina, but we 
predict that this process would require several additional days, as in larval goldfish (Raymond, 1985).

We also note that the intervals between cell birth and opsin expression in retinas of adult goldfish, as shown in the present study, are much longer than those found previously in embryonic goldfish, where all types of opsin are expressed in the retina within 5 days of fertilization (Stenkamp et al., 1996). Therefore, the slower rate of ocular growth and retinal cell addition in adult goldfish ( ohns and Easter, 1976) is accompanied by a relatively lengthy process of cell differentiation, compared with the rapid pace of cell proliferation and differentiation in goldfish embryos (Stenkamp et al., 1996).

\section{The order of cone opsin expression at the retinal margin is red, green, blue, ultraviolet}

The temporal interval between cone cell birth date and cone opsin expression is directly related to spectral phenotype. In a cohort of cones born at approximately the same time, red cones were the first to express opsin, followed by green cones, then bluecones, then finally ultraviol et cones. This order is identical to the order of onset of opsin expression observed in embryonic goldfish (Stenkamp et al., 1996), and is consistent with that observed in embryonic zebrafish (Raymond et al., 1995). In the earlier studies, it was unclear whether this difference in onset of opsin expression was a result of (1) phenotype-specific order of cell birth followed by similar rates of differentiation, or (2) concomitant cell birth followed by phenotypespecific rates of differentiation. The findings of the present study are consistent with the second possibility, because the timing of opsin expression was phenotype-specific in a cohort of cones born at the same time. However, we cannot conclusively rule out a combination of the above two explanations, and a detailed, embryonic cone birthdating study would be necessary to directly address this issue.

Photoreceptors in the teleost retina are arranged in a crystalline-like mosaic array, in which specific cone cell types have consistent positions relative to each other (Müller, 1952; Engström, 1960; Marc and Sperling, 1976, Raymond et al., 1993). It has been proposed (Raymond, 1995; Stenkamp et al., 1996) that a sequence of inductive cell-cell interactions may be involved in teleost cone mosaic formation, in a manner reminiscent of the cascade of inductive events that lead to photoreceptor formation in Drosophila (Cagan and Zipursky, 1992). The cone mosaic is established early in development in both zebrafish (Larison and BreMiller, 1990; Raymond et al., 1995) and goldfish (Stenkamp et al., 1996), and cone photoreceptors differentiate in an order that predicts their location in the mosaic (Raymond et al., 1995; Stenkamp et al., 1996). New cones are continuously recruited into the cone mosaic at the retinal margin of the adult goldfish, and in the present study the order of cone opsin expression at the margin was found to be identical to the order observed in the embryo, suggesting a conservation of developmental mechanisms involved in the establishment of specific cell position as well as spectral phenotype. The varying temporal intervals between cell birth and opsin expression for the different cone photoreceptor types are consistent with a mechanism in which position-dependent microenvironmental signals direct the differentiation (and perhaps commitment) of specific spectral phenotypes. The nature of these putativesignals is the subject of ongoing study.

\section{Temporal and spatial relationships of developing rods and cones suggest a role for cell-cell interactions}

The cartoon in Figure 6 also illustrates the changing relationships between rods and cones, beginning with their respective origins as postmitotic, undifferentiated cells, to their final locations as differentiated photoreceptors. It is important to emphasize that although Figure 6 gives the impression of lateral movement of developing photoreceptors, retinal cells actually maintain the same neighbor relationships as they differentiate and while additional cells accumulate peripherally (see also Fig. 1). Despite their disparate sites of genesis, the onset of opsin expression in cones and rods roughly coincides spatially (Fig. 5A). The steps involved in cone differentiation were described above; the steps involved in rod differentiation, as determined by several previous studies (Raymond and Rivlin, 1987; Knight and Raymond, 1990) as well as the present one, are described next.

The ultimate source of all new neurons in the adult retina is the circumferential germinal zone, although the cells (rod precursors) that later give rise to rods remain proliferative and undifferentiated. It is believed that these progenitor cells are initially sequestered in the inner nuclear layer, and their progeny migrate radially to the ONL and continue to divide (Raymond and Rivlin, 1987). We are currently attempting to measure the temporal delay between the generation of these cells in the germinal zone, and their appearance in the ONL as rod precursors; preliminary evidence suggests that this delay is on the order of 4 to 6 days in juvenile/adult goldfish (Stenkamp and Raymond, unpublished observations). Some of the progeny of the rod precursors differentiate into rods, and they do so rapidly compared with cones, in that they express rod opsin mRNA within 3 days (present study), and rod opsin protein within 4 days (Knight and Raymond, 1990).

After production of photoreceptor progenitors in the germinal zone, rod and cone developmental pathways therefore become separated in space as well as in time, until shortly before the onset of opsin expression, when these two differentiating cell types re-encounter each other in the ONL. Because cones express IRBP before they encounter an opsin-expressing rod, phenotypic determination of cones must take place in the absence of direct contact with immature or differentiated rods. However, expression of a specific cone opsin is delayed until opsinexpressing rods have differentiated nearby. Based on these observations, we suggest the following potential mechanisms whereby cone and rod differentiation may be coordinated: (1) immature cones and rods are induced to express opsin at the same location by a signal either from the underlying inner retina or from the overlying retinal pigmented epithelium (RPE); (2) photoreceptor commitment occurs at or shortly after cell birth, but an internal timing mechanism, which is slower for cones than for rods, allows the simultaneous expression of opsin mRNA in rods and red cones; (3) committed cones induce nearby postmitotic rods to rapidly differentiate and express opsin; (4) rapidly differentiating rods induce immature cones to select a specific spectral phenotype. A putative signaling mechanism originating from the RPE or inner retina (mechanism 1) would require the precise timing of differ- 
ent soluble signals and/or different receptor combinations in the responding cells if a single signaling source were to coordinate sequential opsin expression in multiple cone cell types. Although not impossible, this alternative seems unnecessarily complex. The presence of an internal timing mechanism specific to each committed cell type (mechanism 2) also seems unlikely because the exact temporal interval between cell birth and opsin mRNA expression varies from fish to fish, and from embryo to adult (see Stenkamp et al., 1996), whilethe relativetiming of rod and cone opsin expression remains consistent. The findings of the present study are most supportive of mechanisms 3 and 4, and suggest a model for photoreceptor commitment and differentiation that involves sequential specification of spectral phenotype as a consequence of instructive cellcell interactions between rods and cones and among cone subtypes. However, the present evidence supporting this model is largely circumstantial: specific cone opsin expression is delayed until cones are near differentiating rods (in the case of red cones), or until all other cone types have expressed opsin (in the case of UV cones). Weare currently investigating potential strategies for selectively interfering with production of specific photoreceptor subtypes to experimentally test this model.

\section{ACKNOWLE DGMENTS}

The authors thank Koji Nakanishi (Columbia University), Fumio Tokunaga (Osaka University), and Federico Gonzalez-F ernandez (University of Virginia) for their kind gifts of CDNA plasmids. This work was supported by NSF IBN-9222046 (P.A.R.) and NIH F 32 EY 06612 (D.L.S.).

\section{LITERAT URE CITE D}

Barthel, L.K., and P.A. Raymond (1990) Improved method for obtaining 3-micron cryosections for immunocytochemistry. J . Histochem. Cytochem. 38:1383-1388.

Barthel, L.K., and P.A. Raymond (1993) Subcellular localization of $\alpha$-tubulin and opsin mRNA in the goldfish retina using digoxigenin-labeled CRNA probes detected by alkaline phosphatase and HRP histochemistry. J . Neurosci. Methods 50:145-152.

Blaxter, J.H.S. (1975) The eyes of Iarval fish. In M.A. Ali (ed): Vision in Fishes: New Approaches to Research. New York: Plenum, pp. 427-443.

Blaxter, J .H.S., and M. Staines (1970) Pure-cone retinae and retinomotor responses in larval teleosts. J . Marine Biol. 50:449-460.

Branchek, T., and R. BreMiller (1984) The devel opment of photoreceptors in thezebrafish, Brachydanio rerio: I . Structure. J . Comp. Neurol. 224:107115.

Brown, M.E. (1957) Experimental studies on growth. In M.E. Brown (ed): The Physiology of Fishes. New York: Academic Press, pp. 361-400.

Cagan, R.L., and S.L. Zipursky (1992) Cell choice and patterning in the Drosophila retina. In M. Shankland and E.R. Macagno (eds): Determinants of Neuronal I dentity. New York: Academic Press, pp. 189-224.

Carter-Dawson, L.D., and M.M. LaVail (1979) Rods and cones in the mouse retina. II. Autoradiographic analysis of cell generation using tritiated thymidine. J . Comp. Neurol. 188:263-272.

Carter-Dawson, L., R. Alvarez, S.-L. Fong, G. Liou, H. Sperling, and C.D.B. Bridges (1986) Rhodopsin, 11-cis vitamin A and interstitial retinalbinding protein (IRBP) during retinal development in normal and rd mutant mice. Dev. Biol. 116:431-438.

Cohen, A. (1972) Rods and cones. In M.G.F. Fourtes (ed): Handbook of Sensory Physiology, vol. 7. New York: Springer, pp. 63-109.

Engström, K. (1960) Conetypes and cone arrangement in the retina of some cyprinids. Acta Zool XLI:1-19.

Evans, B.I ., and R.D. Fernald (1993) Retinal transformation at metamorphosis in the winter flounder (Pseudopleuronectes americanus). Vis. Neurosci. 10:1055-1064.
Fernald, R.D. (1989) Retinal rod neurogenesis. In B.L. Finlay and D.R Sengelaub (eds): Development of the Vertebrate Retina. New York: Plenum Press, pp. 31-42.

Gonzalez-Fernandez, F., and J .I. Healy (1990) Early expression of the gene for interstitial retinol-binding protein during photoreceptor differentiation suggests a critical role of the interphotoreceptor matrix during retinal development. J . Cell Biol. 111:2775-2784.

Gratzner, H.G. (1982) Monoclonal antibody to 5-bromo- and 5-iododeoxyuridine: A new reagent for detection of DNA replication. Science 218:474475.

Harris, W.A., and V. Hartenstein (1991) Neuronal determination without cell division in Xenopus embryos. Neuron 6:499-515.

Harris, W.A., and S.L. Messersmith (1992) Two cellular inductions involved in photoreceptor determination in the Xenopus retina. Neuron 9:357372.

Hauswirth, W.W., A.V.D. Langerijt, A.M. Timmers, G. Adamus, and R.J . Ulshafer (1992) Early expression and localization of rhodopsin and interphotoreceptor retinoid-binding protein (IRPB) in the developing fetal bovine retina. Exp. Eye Res. 54:661-670.

Hisatomi, O., T. Satoh, L.K. Barthel, D.L. Stenkamp, P.A. Raymond, and F. Tokunaga (1996) Molecular cloning and characterization of the putative ultraviolet-sensitive visual pigment of goldfish. Vision Res. 36:933-939.

Hollyfield, J .G., S.J . Fliesler, M.E. Rayborn, S.-L. Fong, R.A. Landers, and C.D.B. Bridges (1985) Synthesis and secretion of interstitial retinolbinding protein by the human retina. Invest. Ophthalmol. Visual Sci. 26:58-67.

J ohns, P. Raymond (1977) Growth of the adult goldfish eye. III. Source of the new retinal cells. J . Comp. Neurol. 176:343-358.

J ohns, P. Raymond (1982) Formation of photoreceptors in larval and adult goldfish. J . Neurosci. 2:178-198.

J ohns, P. Raymond, and S.S. Easter (1976) Growth of the adult goldfish eye. II. Increase in retinal cell number. J . Comp. Neurol. 176:331-342.

J ohns, P. Raymond, and R.D. Fernald (1981) Genesis of rods in teleost retina. Nature 271:360-362.

J ohnson, R.L., K.B. Grant, T.C. Zankel, M.F. Boehm, S.L. Merbs, J . Nathans, and K. Nakanishi (1993) Cloning and expression of goldfish opsin sequences. Biochemistry 32:208-214.

Kljavin, I.J . (1987) Early development of photoreceptors in the ventral retina of the zebrafish embryo. J . Comp. Neurol. 260:461-471.

Knight, J .K., and P.A. Raymond (1990) Time course of opsin expression in devel oping rod photoreceptors. Development 110:1115-1120.

Larison, K.D., and R. BreMiller (1990) Early onset of phenotype and cell patterning in the embryonic zebrafish retina. Development 109:567576.

LaVail, M.M., D.H. Rapaport, and P. Rakic (1991) Cytogenesis in the monkey retina. J . Comp. Neurol. 309:86-114.

Mack, A.F., and R.D. Fernald (1995) New rods move before differentiating in adult teleost retina. Dev. Biol. 170:136-141.

Marc, R.E., and H.G. Sperling (1976) The chromatic organization of the goldfish cone mosaic. Vision Res. 16:1211-1224.

Müller, H. (1952) Bau und Wachstum der Netzhaut des Guppy (Lebistes reticulatus). Zool. J b. 63:275-324.

Munk, O., and J .M. J ørgensen (1983) Mitoses in the retina of two deep-sea teleosts. Vidensk. Medd. Dan. Naturhist. Foren. 144:75-81.

Porello, K., S.P. Bhat, and D. Bok (1991) Detection of interphotoreceptor retinoid-binding protein (IRBP) mRNA in human and cone-dominant squirrel retinas by in situ hybridization. J. Histochem. Cytochem. 39:171-176.

Raymond, P.A. (1985) Cytodifferentiation of photoreceptors in larval goldfish: Delayed maturation of rods. J . Comp. Neurol. 236:90-105.

Raymond, P.A. (1995) Development and morphological organization of photoreceptors. In M.B.A. Djamgoz, S.N. Archer, and S. Vallerga (eds): Neurobiology and Clinical Aspects of the Outer Retina. London: Chapman and Hall, pp. 1-23.

Raymond, P.A., L.K. Barthel, M.E. Rounsifer, S.A. Sullivan, and J.K. Knight (1993) Expression of rod and cone visual pigments in goldfish and zebrafish: A rhodopsin-like gene is expressed in cones. Neuron 10:1161-1174

Raymond, P.A., L.K. Barthel, and G.A. Curran (1995) Developmental patterning of rod and cone photoreceptors in embryonic zebrafish. J . Comp. Neurol. 359:537-550.

Raymond, P.A., and P.K. Rivlin (1987) Germinal cells in the goldfish retina that produce rod photoreceptors. Dev. Biol. 122:120-138. 
Reh, T.A. (1991) Determination of cell fate during retinal histogenesis: intrinsic and extrinsic mechanisms. In D.M. Lam and C.J . Shatz (eds): Devel opment of the Visual System. Cambridge, MA: The MIT Press, pp. 79-94.

Sandy, J .M., and J .H.S. Blaxter (1980) A study of retinal development in larval herring and sole. J . Marine Biol. Assoc. UK 60:59-71.

Sidman, R.L. (1960) Histogenesis of mouse retina studied with thymidine $\mathrm{H}^{3}$. In G.K. Smelser (ed): The Structure of the Eye. New York: Academic Press, pp. 487-506.

Smelser, G.K., V. Ozanics, M. Rayborn, and D. Sagun (1974) Retinal synaptogenesis in the primate Macaca mulatta. Invest. Ophthalmol. Visual Sci. 13:340-361.

Stell, W.K., and F.I. Hárosi (1976) Cone structure and visual pigment content in the retina of the goldfish. Vision Res. 16:647-657.

Stenkamp, D.L., O. Hisatomi, L.K. Barthel, F. Tokunaga, and P.A. Ray- mond (1996) Temporal expression of rod and cone opsins in embryonic goldfish retina predicts the spatial organization of the cone mosaic Invest. Ophthalmol. Visual Sci. 37:363-376.

Szél, A., T. van Veen, and P. Röhlich (1994) Cone differentiation in the retina. Nature 370:336.

van Ginkel, P.R., and W.W. Hauswirth (1994) Parallel regulation of fetal gene expression in different photoreceptor cell types. J . Biol. Chem. 269:4986-4992.

van Veen, T.H., A. Katial, T. Shinohara, D.J. Banett, B. Wiggert, G.J Chader, and J .M. Nickerson (1986) Retinal photoreceptor neurons and pineal ocytes accumulate mRNA for interphotoreceptor retinoid-binding protein (IRBP). FEBS Lett. 208:133-137.

Wagenhorst, B.B., R.R. Rajendran, E.E. Van Niel, R.B. Hessler, A. Bukelman, and F. Gonzalez-Fernandez (1995) Goldfish cones secrete a two repeat IRBP. J . Mol. Evol. 41:646-656. 